\title{
Transnasal Percutaneous Endoscopic Gastrostomy
}

Percutaneous endoscopic gastrostomy (PEG) tubes are the preferred means of feeding for malnourished cancer patients (1). Patients with cancer in the head and neck are at a disadvantage here due to the high failure rate of the endoscopic methods (2). A certain number of patients are unable to open their mouths to a satisfactory degree for the introduction of the gastroscope. In specific situations, however, a PEG can be placed via the transmaxillary route (3).

In two patients in whom we were unable to use oral access, we placed the PEG via the transnasal route instead (Figure 1). The patients were a 52-year-old man with squamous-cell carcinoma of the left tonsil and partial trismus, and a 67-year-old man with a tumor of the tongue and metastasis in the neck region, as well as a pharyngocutaneous fistula. The use of nasogastric endoscopy allowed the placement of a PEG in both cases.

The patients were given intravenous premedication with pethidine and atropine. The otorhinolaryngologist prepared the nose and administered local anesthesia (with a lidocaine spray) in the nasal canal. The gastroscope (Fujinon EG7-FP3, distal end diameter $10.3 \mathrm{~mm}$ ) was then inserted through the nostril. The esophagus was accessed via the inferior nasal passage, the nasopharynx and oropharynx. Before placement of the PEG, a complete esophagogastroduodenoscopy was performed. No procedure-related or lateonset complications occurred.

To our knowledge, this technique of placing a PEG has not previously been described. The method described here can be used for diagnostic and therapeutic purposes in cases in which the oral route is not accessible.

A. Taller', E. Horváth ${ }^{2}$, L. Harsányi ${ }^{3}$, Zs. Balatoni ${ }^{2}$, L. Iliás ${ }^{\prime}$

' Second Dept. of Internal Medicine

${ }^{2}$ Dept. of Head and Neck Surgery, Uzsoki Municipal Hospital, Budapest, Hungary

${ }^{3}$ First Dept. of Surgery, Semmelweis University, Budapest, Hungary

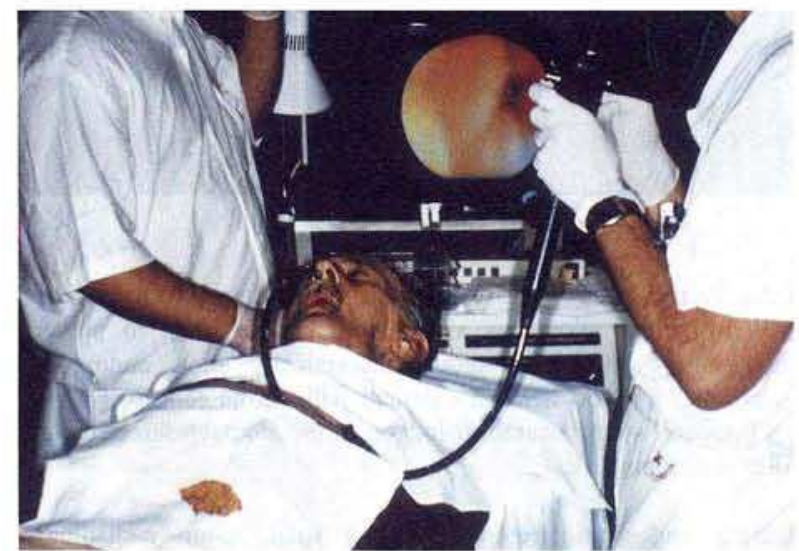

Figure 1: The endoscope is introduced into the upper gastrointestinal tract through the nose.

\section{References}

1. Larson DE, Burton DD, Schroeder KW, DiMagno EP. Percutaneous endoscopic gastrostomy: indications, success, complications, and mortality in 314 consecutive patients. Gastroenterology 1987; $93: 48-52$.

2. Hunter JG, Lauretano L, Shiletto PC. Percutaneous endoscopic gastrostomy in head and neck cancer patients. Ann Surg 1989; 210:42-6.

3. Grier JF, Goldman DE, Gholson CF. Transmaxillary, percutaneous endoscopic gastrostomy. Gastrointest Endosc 1994; 40: $778-9$.

Corresponding Author

A. Taller, M.D., Second Dept. of Internal Medicine

Uzsoki Municipal Hospital, Uzsoki u. 29

1145 Budapest, Hungary

Fax: 36-1-2514069 